Part of Journal of Research of the National Bureau of Standards, Volume 15, December 1935

\title{
EFFECT OF HUMIDITY IN HOT-WIRE ANEMOMETRY
}

\author{
By Galen B. Schubauer
}

\section{ABSTRACT}

The possibility of a humidity effect on the heat loss from a heated wire in an air stream has long been recognized, but only recently was the effect found experimentally by Paeschke. The effect is to increase the heat loss at the higher humidities. The present paper describes an experiment conducted to verify the existence of the effect. The results show an increase of heat loss per degree rise in wire temperature of about 2 percent for a change in the partial pressure of water vapor from 0.007 to 0.023 , or a change in relative humidity from 25 to 70 percent in the neighborhood of $25^{\circ} \mathrm{C}$. The effect may be explained by an effect of humidity on the thermal conductivity of air.

A hot-wire anemometer consists essentially of a small electrically heated wire, usually of platinum, which may be exposed to an air stream in which the speed is to be measured. Associated apparatus is required for controlling the heating current and measuring the rate of heat loss from the wire. The theoretical relation between the rate of heat loss and the air speed is given by the following formula due to King: ${ }^{1}$

where

$$
\frac{H}{\Delta T}=4.18 l(k+2 \sqrt{\pi k \rho c r V}),
$$

$H=$ heat loss from the wire to the surrounding air in watts.

$\Delta T=$ temperature elevation of the wire above the temperature of the surrounding air in degrees C.

$l=$ length of the wire in centimeters.

$k=$ thermal conductivity of air in cgs units.

$\rho=$ density of air in cgs units.

$c=$ specific heat of air at constant volume in cgs units.

$r=$ radius of wire in centimeters.

$V=$ air speed in centimeters per sec.

Since the heat lost from the wire by radiation is neglected in equation 1 and also since $k$, near the wire, and $r$ may not be known with sufficient accuracy, the hot-wire anemometer cannot be used as an absolute instrument, but must be calibrated by measuring $H / \Delta T$, or some related quantity, in a stream of known speed. It is the universal experience of those working with hot-wire anemometers that the calibration cannot be relied upon over long periods of time. Aside from such changes as may occur due to damaging of the wire in handling, other changes of a seemingly erratic nature take place which are difficult to account for, and which have done much to discourage the use of hot-wire anemometers in precise work.

1 L. V. King, On the convection of heat from small cylinders in a stream of fluid: Determination of the convection constants for small platinum wires with application to hot-wire anemometry. Phil. Trans. Roy. Soc. 214, 373, (1914). 
It has long been suspected that changes in the heat loss from the wire may occur through the effect of humidity on such quantities as $k, \rho$, and $c$ in equation 1 . It is known that the presence of water vapor in the air increases the thermal conductivity for small partial pressures of the vapor, ${ }^{2}$ and for this reason an increase of heat loss with increasing humidity is to be expected. The effect of humidity on the product of density and specific heat is exceedingly small and as a contributing factor can probably be neglected. While it is possible to predict the direction of the effect from equation 1 , it is difficult to estimate its magnitude due to the neglected radiation loss. Furthermore the value of $k$ for air containing small amounts of water vapor is not definitely known at temperatures below $80^{\circ} \mathrm{C}$.

An increase in the heat loss from a wire as the result of increasing the humidity was recently found experimentally by W. Paeschke. ${ }^{3}$ An earlier attempt to find an effect of humidity, made by Kennelly and Sanborn ${ }^{4}$ in connection with the effect of air density on the heat loss from a wire, led to the conclusion that the effect, if present, was too small to be detected. However, in the latter tests, no humidity measurements were made.

The effect was investigated at the National Bureau of Standards in a small return-circuit wind tunnel in which the relative humidity could be varied between 25 and 70 percent. The wire, which was of platinum $0.05 \mathrm{~mm}$ in diameter and $27.0 \mathrm{~mm}$ long, was placed in the working section about $10 \mathrm{~cm}$ from a standard pitot-static tube by which the speed was measured. The direction of the air flow was upward and normal to the wire. All accompanying apparatus, such as current controls and potentiometer, were located outside the tunnel where the humidity remained essentially constant.

The relative humidity in the tunnel could be raised from about 25 to near 70 percent in 2 or 3 hours by placing water in troughs along the tunnel walls and allowing a large area of cloth, inside the tunnel on the return-duct walls, to become wet by capillary attraction. The removal of the water and the circulation of outside air through the tunnel lowered the relative humidity to within a few percent of the outside value in about 4 hours. It was possible therefore to change rather quickly from one condition to another without the necessity of changing the temperature or disturbing the experimental setup. The relative humidity was measured by a hair hygrometer, which had previously been calibrated.

Since the air temperature changed but little, varying only between 23 and $27^{\circ} \mathrm{C}$, and the barometric pressure remained essentially constant at $756 \mathrm{~mm}$ of mercury, the humidity changes were really changes in the absolute humidity. By taking into account the temperature changes, the readings of the hygrometer were converted into absolute numidities. These are expressed here in terms of the partial pressure of water vapor, denoted by $p_{2}$.

The experimental procedure consisted in measuring the potential drop across the wire at various wind speeds for a constant heating current. The wire temperature was allowed to vary with the speed. Using these data together with the temperature resistance curve for

\footnotetext{
${ }^{2}$ H. A. Daynes, Gas Analysis by Measurement of Thermal Conductivity. Cambridge University Press, p. 23 (1933).

3 W. Paeschke, Feuchtigkeitseffekt bei Hitzdrahtmessungen, Physik Z. 36, 564 (1935)

A. E. Kennelly and H. S. Sanborn, The influence of atmospheric pressure upon the forced thermal convection from small electrically heated platinum wires, Proc. Am. Phil. Soc. 52, 55 (1914).
} 
the wire, which was obtained by measurements of the wire resistance at the temperature of the surrounding air, $H / \Delta T$, the heat loss per degree rise in temperature, was calculated. From a number of such determina-

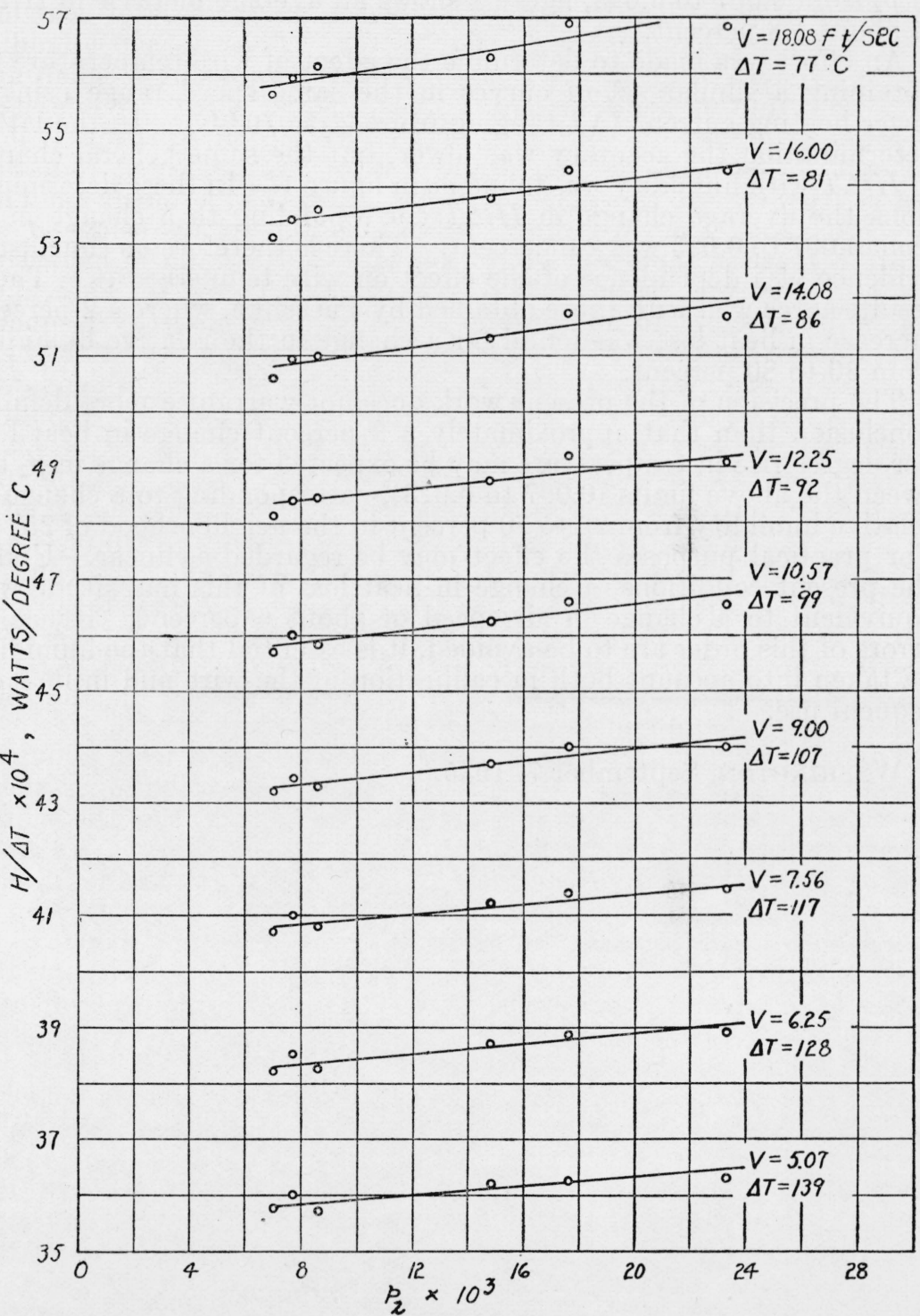

FIGURE 1.-Variation of heat loss per degree rise in wire temperature with variation in humidity.

$\left(p_{2}=\right.$ partial pressure of water vapor.)

tions corresponding to several relative humidities ranging from 25 to 70 percent, the variation in $H / \Delta T$ with humidity was determined.

The results obtained with a heating current of 0.464 ampere are summarized in figure 1. The spacing between curves in this figure 
is determined by the change in $H / \Delta T$ in going from one speed to the next. The approximate temperature elevation $\Delta T$ of the wire corresponding to the various speeds is also shown. Considering a change in $p_{2}$ from 0.007 to 0.023 , figure 1 shows an average increase in $H / \Delta T$ of about 1.8 percent.

An effort was made to determine the effect of wire temperature by obtaining a similar set of curves in the same speed range using a lower heating current ( $\Delta T$ ranging from 42 to $70^{\circ} \mathrm{C}$ ). In the latter determination the accuracy was lower, but the same general change in $H / \Delta T$ with humidity was found as in figure 1 . In these determinations the average change in $H / \Delta T$ corresponding to a change in $p_{2}$ from 0.007 to 0.023 was 2.0 percent. There is therefore no conclusive evidence of a dependence of the effect on wire temperatures. These results agree well with those obtained by Paeschke, where a 2-percent increase in heat loss was found for a change in the relative humidity from 30 to 80 percent.

The precision of the present work does not warrant a more definite conclusion than that approximately a 2 percent change in heat loss per degree rise in temperature may be expected for a change in $p_{2}$ between the above limits $(0.007$ to 0.023$)$, corresponding to a change in relative humidity from 25 to 70 percent in the neighborhood of $25^{\circ} \mathrm{C}$. For practical purposes the effect may be regarded as linear. Under the present conditions, a change in heat loss of this magnitude was equivalent to a change in air speed of about 6 percent. Hence, if errors of this order are to be avoided, it is essential that the humidity be taken into account both in calibration of the wire and in its subsequent use.

Washington, September 7, 1935. 